\title{
Characterization of Particles Transmitted by Wind from Waste Dump of Phosphatic Fertilizers Plant Deposited on Biological Sample Surfaces
}

\author{
M.I. Szynkowska, A. Pawlaczyk and J. Rogowski \\ Institute of General and Ecological Chemistry, Technical University of Lodz, Łódź, \\ Poland
}

\section{Introduction}

There are many methods available aiming at studying atmospheric contamination but often their application is limited by problems connected with sample preparation difficulties or an insufficient amount of material for analysis. Therefore, there is an increasing necessity of applying methods which enable a direct solid sample characterization and provide information concerning the state of environmental pollution (Szczepaniak\&Biziuk, 2003). Surface analysis techniques have become more and more widely used in recent years and their rapid development since 1970s has resulted in many applications including probing physical and chemical properties of surface. The thickness of the studied surface layer depends upon the method employed and varies from a few uppermost layers to several microns deep (Robinson, 1995; Szczepaniak\&Biziuk, 2003; Szynkowska, 2005). Scanning electron microscopy with energy-dispersive X-ray analysis (SEM-EDS) and time-of-flight secondary ion mass spectrometry are powerful methods allowing a direct observation, comparison and characterization of different spectrum of materials. What is more, a large depth of field gives an opportunity to investigate even three-dimensional objects, which is especially significant in observation of usually very heterogeneous biological samples (Goldstein et al., 1992; Seyama \&Soma, 2003; Seyama, 2003; Szynkowska, 2005). The techniques mentioned above are considered a relatively fast and basically non-destructive approach, which can be successfully used as a complementary method to the wet chemical analysis requiring sample homogenization and dissolution (Kempson\&Skinner, 2005; Szynkowska et al., 2008a; Szynkowska et al., 2008b; Williamson et al., 2004). Additionally, XRD technique can be applied in environmental monitoring research to identify crystalline phases of studied samples.

Phosphogypsum deposited in the phosphatic fertilizer waste disposal place in Wiślinka near Gdańsk (Northern Poland) is a main by-product of a wet process of phosphoric acid production. During the wet process phosphoric acid is produced by the reaction of phosphate rock with sulfuric acid, and then used for the production of phosphatic fertilizers. Phosphoric acid and phosphogypsum obtained in the wet process contain a number of impurities like calcium sulfate dehydrate and HF. For every ton of phosphoric acid obtained even up to 5 tons of this waste by-product are produced. The chemical 
composition of by-products and the quantity of impurities depend on the origin of the phosphate rock used in the phosphoric acid industry as well as the dissimilarities in the parameters of the process plant operation or the age of phosphogypsum.

Dumping of phosphogypsum into open air can create environmental and health concerns as the piled material, dominated mainly by calcium sulphate dehydrate (94-98\% wt.), contains approximately up to $5-6 \%$ of many impurities including heavy metals, fluoride and radionuclides, which have been identified as a potential environmental hazard. These toxic substances can be transported by wind over long distances or percolate through the dump and, in consequence, contaminate soil or groundwater. This continuous process may lead to the increase in the content of spread substances in various components of our environment and can be built into the food chain. Therefore, more detailed studies are necessary in order to fully understand the transfer process of toxic substances into the adjacent environment and to assess their impact (Al-Masri et al., 2004; Arocena et al., 1995; Rutherford et al., 1995).

The increasing awareness about possible negative effects caused by elevated levels of toxic substances not only in air, water or soil, but especially in biological material has caused a huge development of plant studies as a complementary tool to instrumental methods. The amount, size or composition of trapped surface material depend on many factors, e.g. distance from the source of pollution or wind strength. The surface characterization of biological samples using SEM-EDS and ToF-SIMS methods could be especially helpful in understanding where and how airborne particulate matter becomes incorporated into or is lost from the plant matrix as well as to assign a specific type of particles to their potential origin (Kempson\&Skinner, 2005; Szynkowska et al., 2008b). SEM-EDS and ToF-SIMS are versatile tools particularly used for morphological and chemical characterization of various materials, which cover a number of areas of application. Nowadays they are employed, for example in environmental and forensic researches, due to their unique properties such as almost a non-destructive analysis and a relatively small amount of sample required. XRD analysis can be used to identify crystalline phases in various phosphate rock and phosphogypsum samples.

The main objective of this chapter was to investigate the possible occurrence of dusting process by analyzing the atmospheric particulates accumulated on the biological surface and to compare them with the particles characteristic of phosphogypsum waste by-product. The other objective of this study was to compare the usefulness of applied methods ( SEM-EDS, ToF-SIMS, XRD) as a complementary tool for the assessment of air pollution.

\section{Material studied}

Biological samples were collected from the area near Gdańsk (Northern Poland), where a huge phosphogypsum waste disposal site is located. In general, the state of pollution of this rural area is affected mainly by the presence of phosphate stack, where approximately over $16 \mathrm{mln}$ tons of phosphogypsum are deposited. In order to correlate the composition of the material deposited on various biological indicators, different phosphogypsum samples as well as phosphate rocks were investigated. The studied rock material comes from Tunisia, Morocco and Syria.

The studied material consists of samples of moss and lichen taken from the neighborhood of a phosphate waste disposal place as well as various phosphogypsum samples (fresh, old, recultivated) stored in the dump and phosphate rock material used in the process of phosphoric acid production. For comparison purposes moss and lichen material was also 
collected from a clean area, not affected by any industrial or environmental activity (Lodz city, Lagiewniki Forest).

\section{Methods}

Scanning electron microscopy with energy dispersive X-ray spectrometer, SEM-EDS (Hitachi, Japan; Thermo Noran, USA) and time- of- flight secondary ion mass spectrometer ToF-SIMS IV (ION-TOF GmbH, Germany) were applied for particle distribution studies and an identification of type and composition of airborne particulate deposited on samples and present in the stored by-product.

Before the SEM-EDS measurements, the samples were placed on carbon plasters and coated with carbon target by Cressington 208 HR system. SEM micrographs, EDS spectra from the single points and chosen microareas and maps showing elemental composition and surface distribution were obtained using the SEM-EDS method. The accelerating voltage was $25 \mathrm{kV}$. The ToF-SIMS positive and negative spectra and images were carried out using ToF-SIMS IV spectrometer equipped with $25 \mathrm{keV}$ bismuth primary ion gun. Primary ion beam current was set to $0.5 \mathrm{pA}$ during analysis. Flood gun was used to compensate for the surface charging during analysis. In the case of phosphogypsum and phosphate rock, the samples were pressed into tablets in order to gain better mass and lateral resolution.

The phase composition of biological, phosphate rock and phosphogypsum samples was examined using polycrystalline difractometer X'PERT PRO MPD (PANanalytical) equipped with a copper tube. HighScore Plus software and PDF-2 database were used for the phase identification.

\section{Results and discussion}

The study was dedicated to verify a possible existence of the emission of dumped material spread by wind into the adjacent environment based on the examination of particulate matter deposited on lichen and mosses samples.

At present SEM-EDS and ToF-SIMS techniques are more and more commonly applied to study particles present on the surface of various biological material as complementary methods to the wet quantitative chemical analysis for an identification of the source of pollution making it possible to distinguish exogenous elements from internal ones. In our studies they were used to provide information about phosphogypsum chemistry, composition and a possible impact on living organisms.

SEM-EDS maps of elemental distribution on phosphogypsum surface revealed many impurities besides main gypsum ingredients. The elements such as $\mathrm{S}, \mathrm{O}, \mathrm{Ca}, \mathrm{Na}, \mathrm{K}$ were quite regularly distributed over the surface of waste. Gypsum formed characteristic geometric sticks resembling posts with the grain size of 20-200 $\mu \mathrm{m}$. Additionally, some amount of much smaller size particles, rather spherical and attached to much bigger gypsum grains and rich in $\mathrm{Al}$, Si (over $2.5 \mu \mathrm{m}$ ), mainly enriched in $\mathrm{F}$ (below $2.5 \mu \mathrm{m}$ ), and containing Ba (around $2.5 \mu \mathrm{m}$ ) and $\mathrm{Sr}$ (even below $1 \mu \mathrm{m}$ ) were observed on EDS maps (Fig. 1). Moreover, SEM-EDS spectra collected from single points of phosphogypsum surface showed other impurities of this waste e.g. the presence of $\mathrm{Fe}, \mathrm{Mn}$ or P, which were not detected on EDS maps performed for whole microareas. It should be pointed out that a potential detection limit of SEM-EDS analysis is about $0.1-0.5 \mathrm{wt}$. \% for most elements. The results obtained from the microscope also indicated some differences among samples taken 
from various parts of the dump, probably caused by a various phosphate rock source and a general decrease in metal intensity during the waste storage. This finding stays in agreement with literature data. There is a general consensus that the content and composition of waste by-product impurities depend mainly on the origin of phosphate rock (besides the type of the wet process applied or efficiency of factory operation) (Arocena et al., 1995; Rutherford et al., 1995; Williamson et al., 2004).

Stockpiled phosphogypsum in Wislinka is derived from various types of phosphoric rock originating mainly from Tunis, Buckra and Togo or Morocco. However, some elements like $\mathrm{Sr}$, Ce or W were observed in higher amounts in fresh samples. Furthermore, EDS spectra demonstrated that a recultiveted sample presents a higher content of e.g. $\mathrm{Ba}, \mathrm{Pb}, \mathrm{Cd}$ and they were in contrast to other phosphogypsum material. Since 2001 the recultivation process with sewage sludge from the mechanical-biological treatment plant (consisting domestic and industrial sewage) has been applied in the considerable part of the disposal place in order to expand luxuriant vegetation, which possibly changed the sanitary conditions and loads of metals.

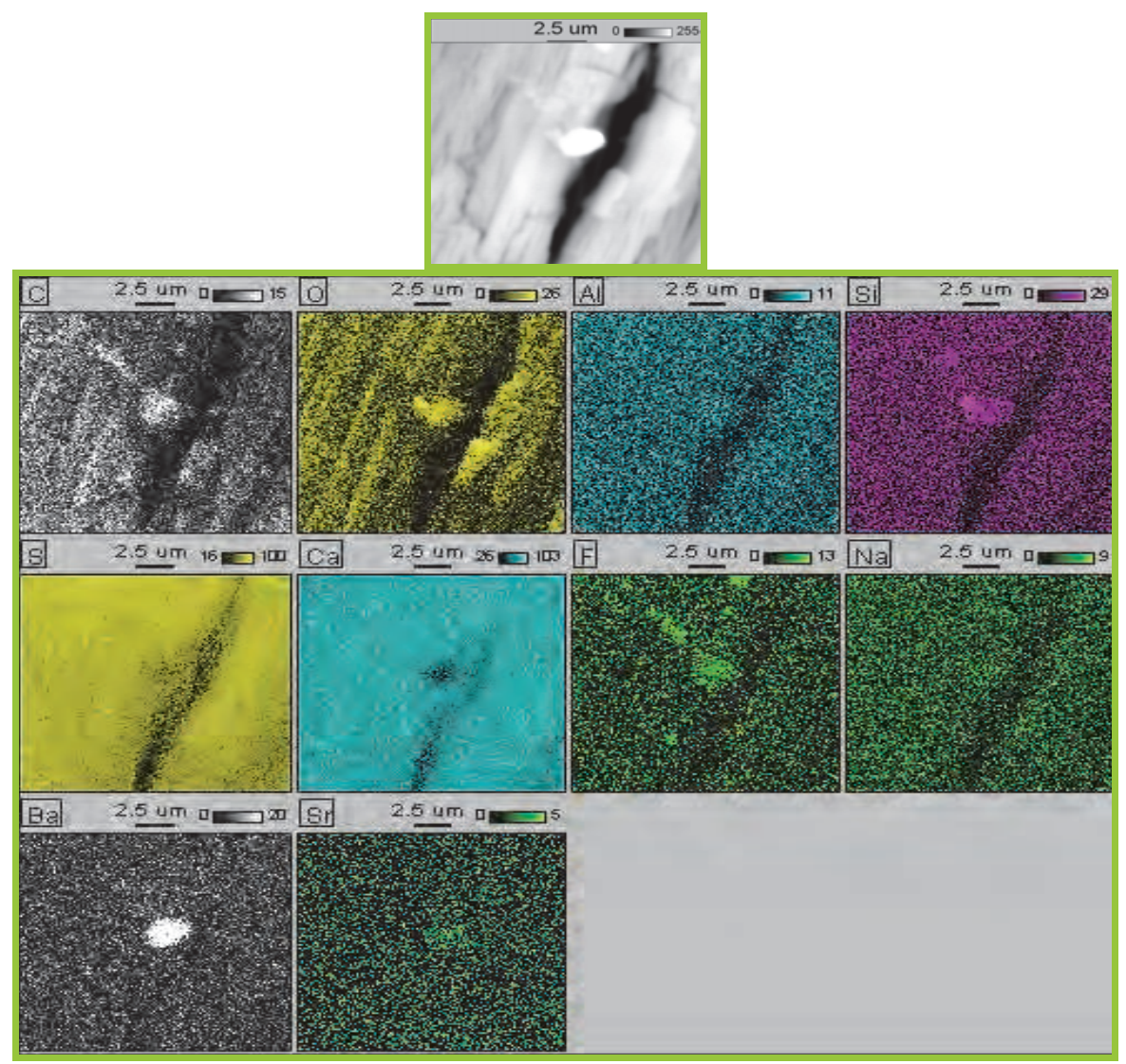

Fig. 1. SEM-EDS micrograph and maps of distribution of elements on the surface of phosphogypsum (x8000) 
The ToF-SIMS analysis showed that phosphogypsum can be characterized by the following characteristic secondary ions: $\mathrm{CaOH}^{+}, \mathrm{Ca}_{2} \mathrm{O}^{+}, \mathrm{CaPO}_{2}{ }^{+}, \mathrm{Ca}_{2} \mathrm{O}_{2}{ }^{+}, \mathrm{CaPO}_{3}{ }^{+}, \mathrm{CaH}^{+}, \mathrm{CN}-, \mathrm{CNO}^{-}$, $\mathrm{Cl}^{-}, \mathrm{SO}-, \mathrm{PO}_{2}^{-}, \mathrm{SO}_{2}^{-}, \mathrm{PO}_{3}^{-}, \mathrm{SO}_{3}^{-}, \mathrm{SO}_{3} \mathrm{H}^{-}, \mathrm{SO}_{4}^{-}, \mathrm{SO}_{4} \mathrm{H}^{-}$and $\mathrm{SiO}^{-}$(Fig. 2). Generally, among phosphogypsum contaminants enhanced levels of fluorine were identified as potential environmental hazards, which restricts its utilization as building materials or agricultural fertilizers. The wastes stockpiled in Wislinka contain about $0.2-0.3 \%$ of soluble fluorine compounds. Moreover, this part of Poland is located in the area with significantly high fluoride concentrations in water of natural origin. A potential leaching process of these impurities may cause their further transfer into the adjacent environment and, in consequence, to the food chain. Summarizing, the obtained information concerning the composition and chemical properties of phosphogypsum is incredibly important from the point of view of the waste management decisions and environmental or health risk assessments.
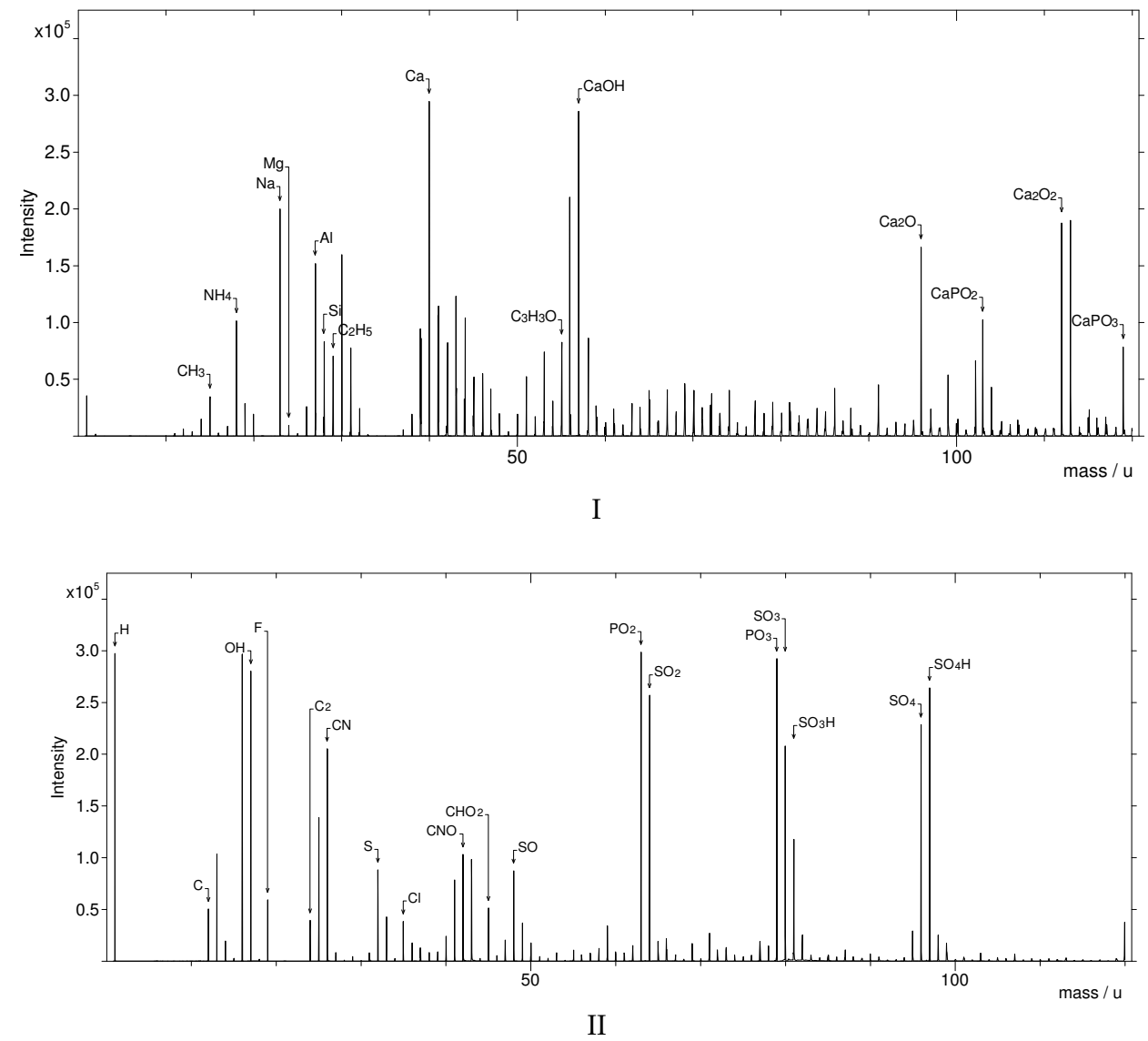

Fig. 2. ToF-SIMS positive (I) and negative (II) ion spectra of phosphogypsum from Wiślinka 
The results of analysis of phosphogypsum particles on moss and lichen surfaces revealed that the composition of analysed phosphogypsum material corresponds to the chemical composition and morphology of particles deposited on biological samples collected from the vicinity of a phosphatic fertilizer dump. There is a well-known fact that elevated concentrations of heavy metals in bioindicators such as lichens in the surroundings of industrial areas are caused mainly by trapping the relatively large particles. This caught particulate matter may remain within the surface over a long time or may be solubilised by e.g. acid precipitation (Kempson\&Skinner, 2005). SEM-EDS analysis of the particulate matter deposited on the surface of chosen biological samples ( moss, lichen) showed apart from the posts typical of gypsum containing mainly $\mathrm{Ca}, \mathrm{O}$ and $\mathrm{S}$ also considerable amounts of particles with the size and composition corresponding to waste impurities identified earlier on the phosphogypsum surface. The grain size can be classified mostly to a very fine fraction below $5 \mu \mathrm{m}$ (Figs. 3-5). The presence of small Fe-rich spherical shaped particles may originate from both the dusting process and high-temperature combustion process. What is more, some irregular particles exceeding $50 \mu \mathrm{m}$ were also found on the biological surfaces (Fig. 4). These enriched in $\mathrm{P}, \mathrm{O}$ and $\mathrm{Si}$ contaminants may be a trace of a wet process of phosphoric acid production.

This work shows that the inhomogenous dispersion of the studied particulate matter on the surface of bioindicators strongly depends on the distance from the waste disposal site. The presence of many windblown air contaminants on the studied surface of biological samples collected in the vicinity of a dump area reflects the level of pollution of this relatively rural area. It was clear that the amount of anthropogenic dust on the biological surface is increasing towards the dump. Therefore, its presence at considerable distances from the dump can prove that there exists a dusting process form the waste disposal place, which can pose a health hazard to the inhabitants by potential inhalation of fine fraction material, which is transported by wind over great distances and contains toxic substances including fluorine and heavy metals.

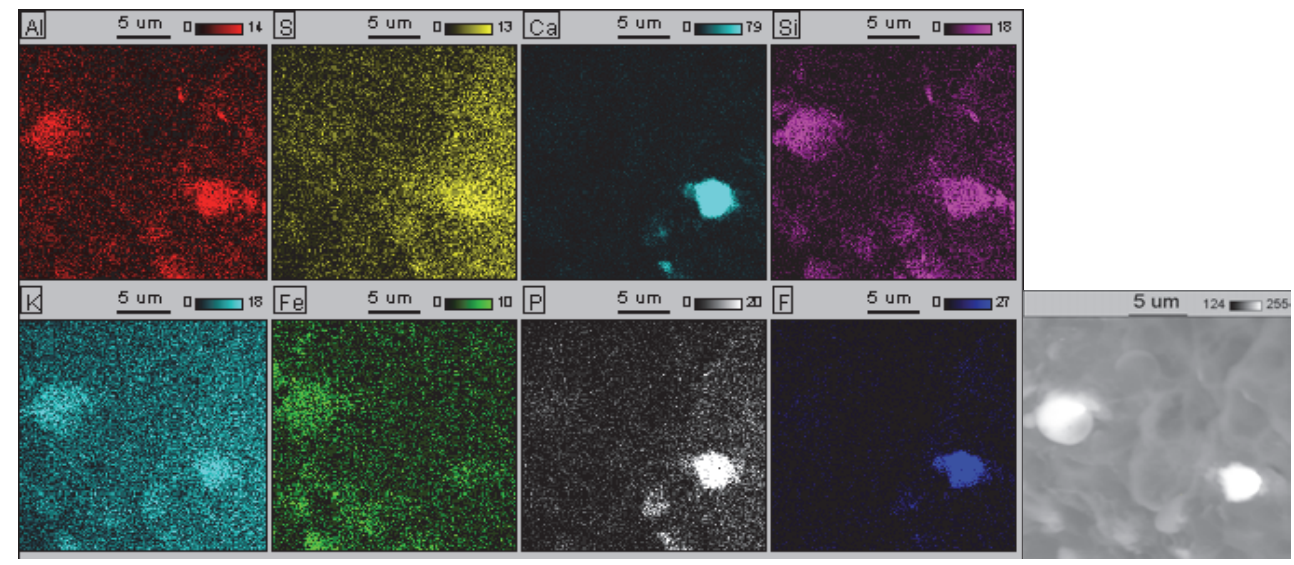

Fig. 3. SEM-EDS micrograph and maps of distribution of particles deposited on lichen surface (x6000). Particles rich in $\mathrm{Al}, \mathrm{S}, \mathrm{Ca}, \mathrm{Si}, \mathrm{K}, \mathrm{Fe}, \mathrm{P}, \mathrm{F}$ are present. 


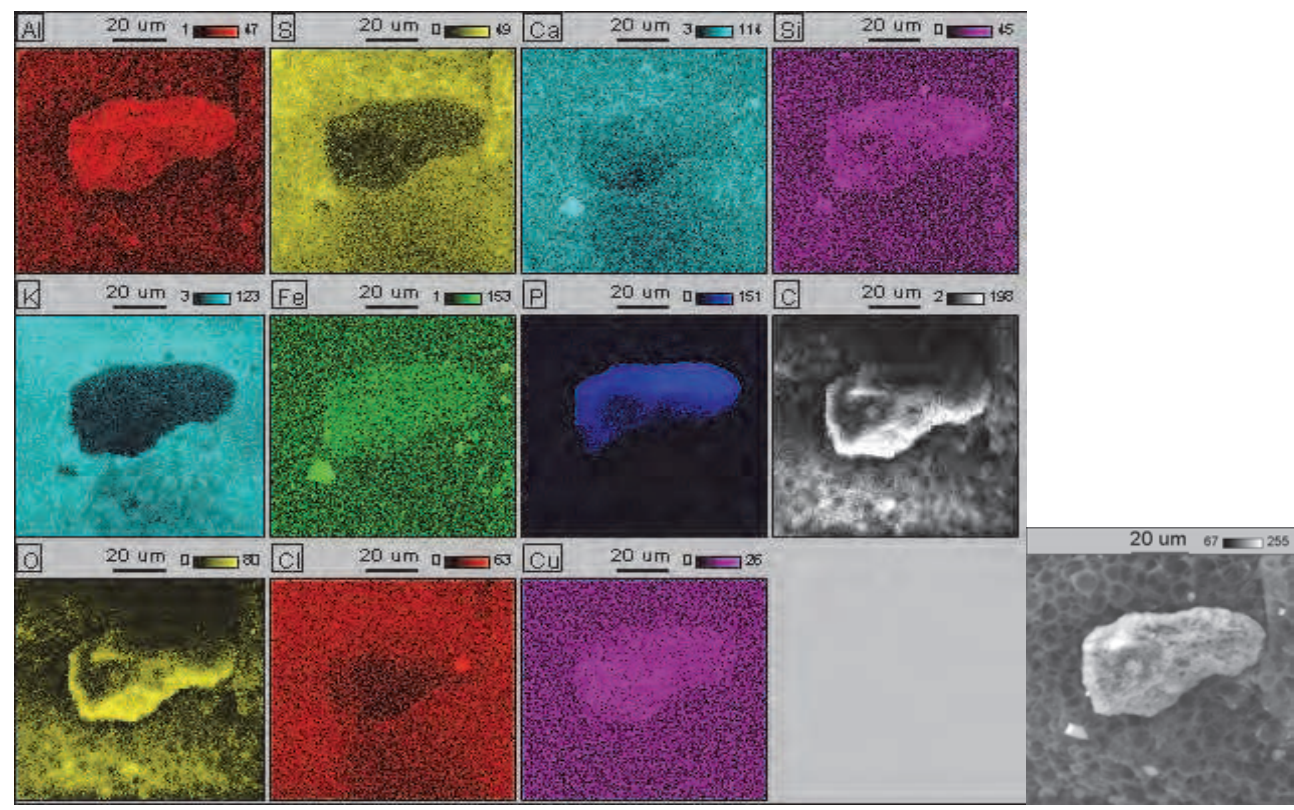

Fig. 4. SEM-EDS micrograph and maps of distribution of particles deposited on lichen surface (x1500). Particles rich in $\mathrm{Al}, \mathrm{Ca}, \mathrm{Si}, \mathrm{Fe}, \mathrm{P}, \mathrm{O}, \mathrm{Cl}, \mathrm{Cu}$ are present.

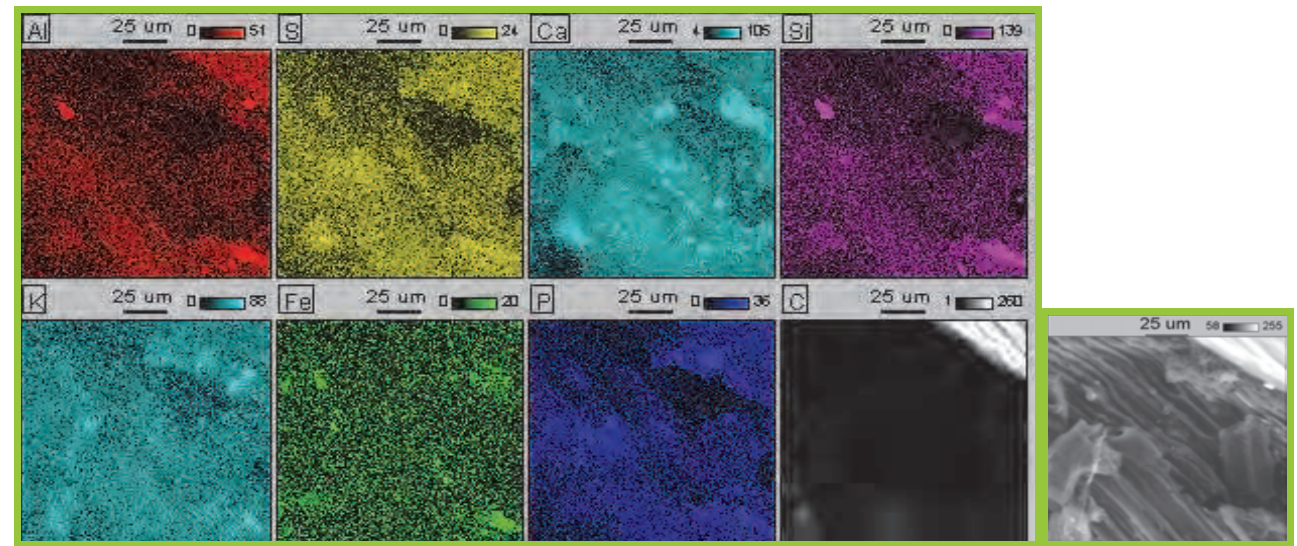

Fig. 5. SEM-EDS micrograph and maps of distribution of particles deposited on moss surface (x1000). Particles rich in $\mathrm{Al}, \mathrm{S}, \mathrm{Ca}, \mathrm{K}, \mathrm{Fe}, \mathrm{P}$ are present.

ToF-SIMS analysis showed that the particles on the studied surfaces of moss and lichen samples are characterized by an emission of the following secondary ions: $\mathrm{Na}^{+}, \mathrm{Mg}^{+}, \mathrm{Al}^{+}$, $\mathrm{Si}^{+}, \mathrm{K}^{+}, \mathrm{Ca}^{+}, \mathrm{CaOH}^{+}, \mathrm{Fe}^{+}, \mathrm{CaPO}_{3}{ }^{+}, \mathrm{F}-, \mathrm{CN}-, \mathrm{S}-\mathrm{Cl}^{-}, \mathrm{PO}_{2^{-}}, \mathrm{SO}_{2^{-}}, \mathrm{PO}_{3^{-}}, \mathrm{SO}_{3^{-}}, \mathrm{SO}_{4^{-}}, \mathrm{SO}_{4} \mathrm{H}^{-}$(Figs. 6 , 7). The material of probable airborne source consisting mainly of $\mathrm{P}$ or $\mathrm{S}$ was characterized by their substantial sizes and amorphous shapes in contrast to other contaminants. 
Field of view: $500.0 \times 500.0 \mu \mathrm{m}^{2}$
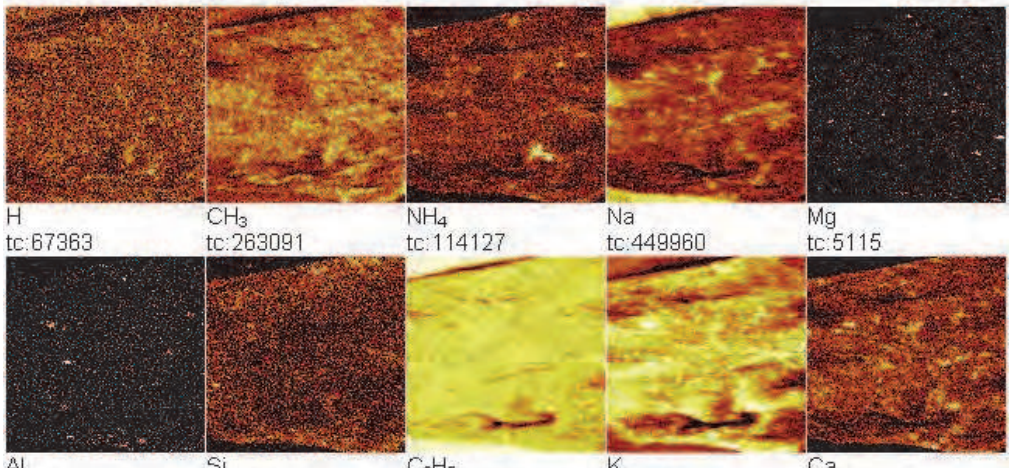

Al

tc: 46580

tc: 114127

tc: 449960

tc. 5115
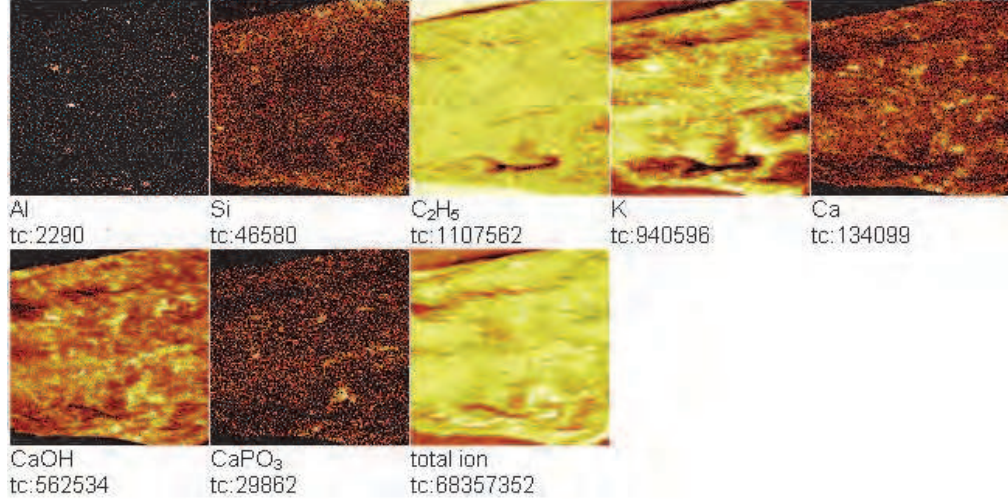

tc: 940596

tc: 134099

I

Field of view. $500.0 \times 500.0 \mu \mathrm{m}^{2}$

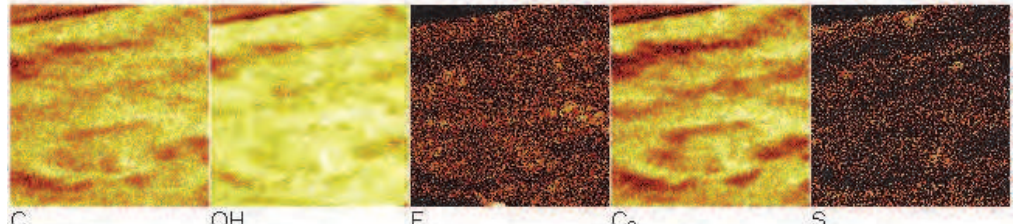

0

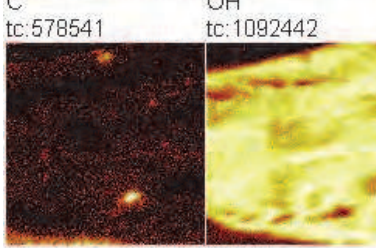

$\mathrm{Cl}$

$\mathrm{CHO}_{2}$

tc: 31464

tc. 543673

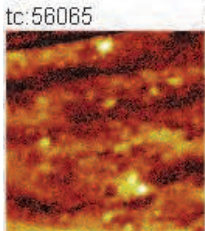

$\mathrm{SO}_{3}$ tc: 1167392

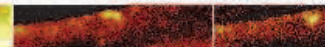

tc: 14073

tc: 561692

$\mathrm{CN}$

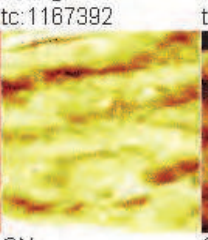

tc: 1254182

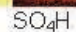

tc: 68885

tc. 377400

tc: 115488

tc: 767698
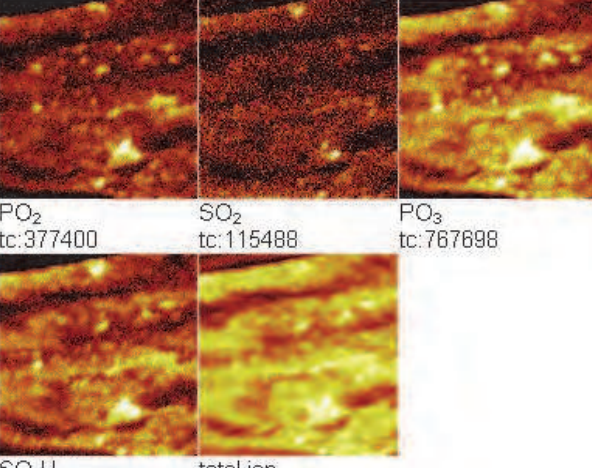

$\mathrm{O}_{3}$
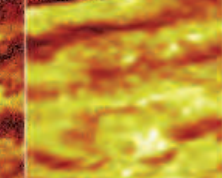

total ion

tc: 55956213

II

Fig. 6. ToF-SIMS positive (I) and negative (II) ion images of moss from Wislinka 

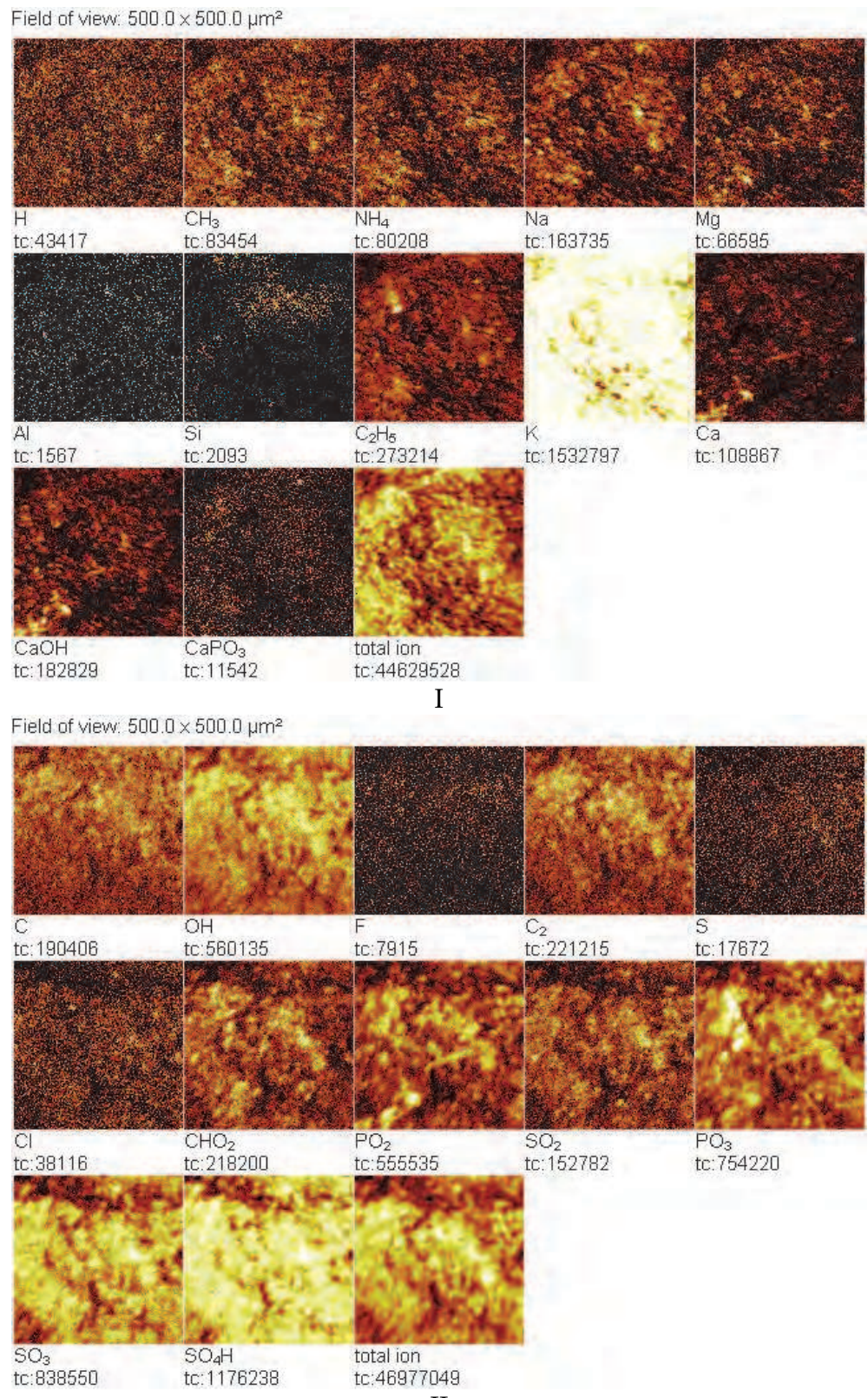

II

Fig. 7. ToF-SIMS positive (I) and negative (II) ion images of lichen from Wiślinka

In order to get a better insight into the process of air industrial contamination, also samples coming from unpolluted places were examined. In general, their surfaces were not covered 
with any deposited particles of anthropogenic origin. Figures 8 and 9 present for comparison ToF-SIMS positive and negative ion images of moss and lichen, respectively from the control site and ecologically clean area.
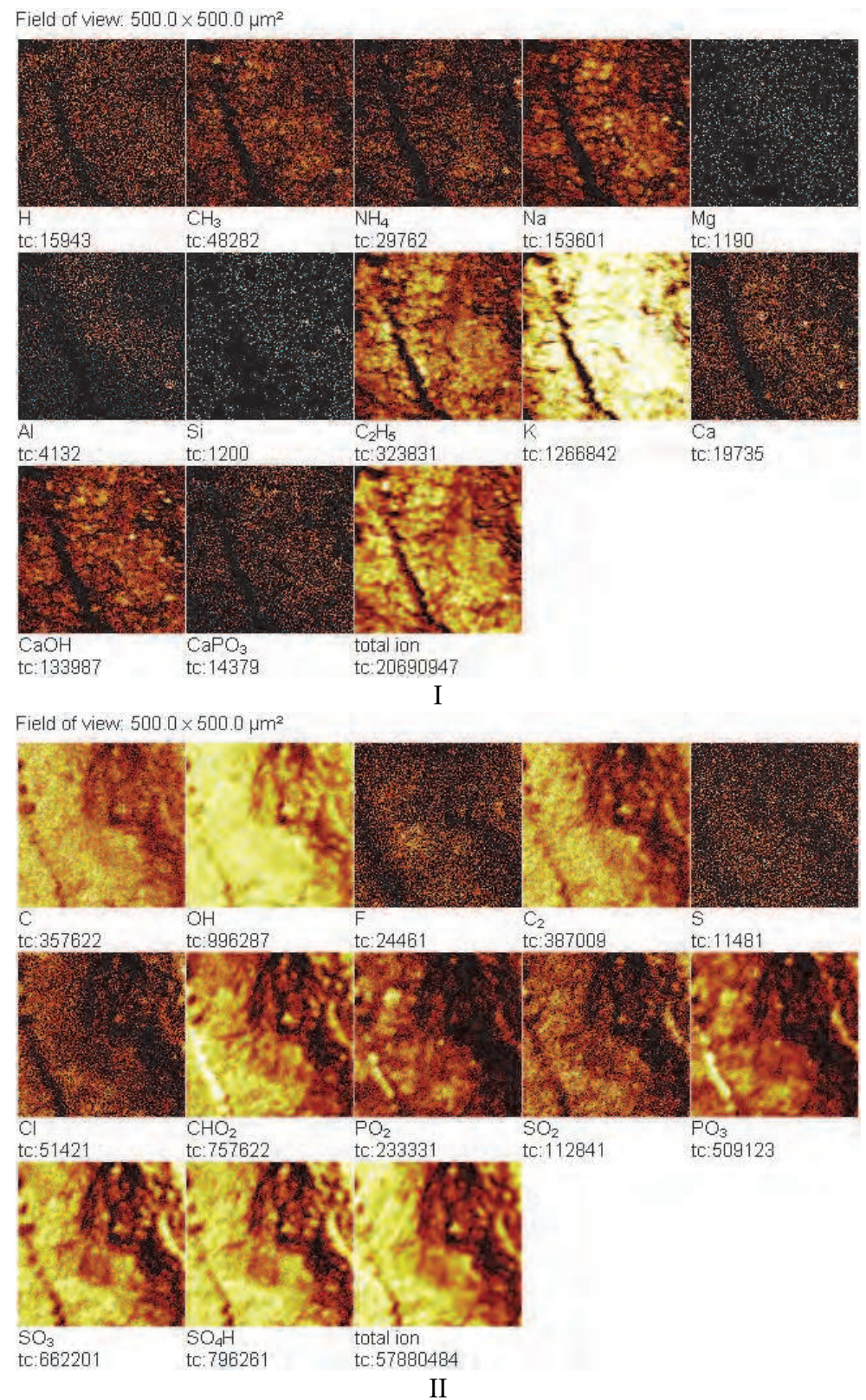

Fig. 8. ToF-SIMS positive (I) and negative (II) ion images of moss from the control site 


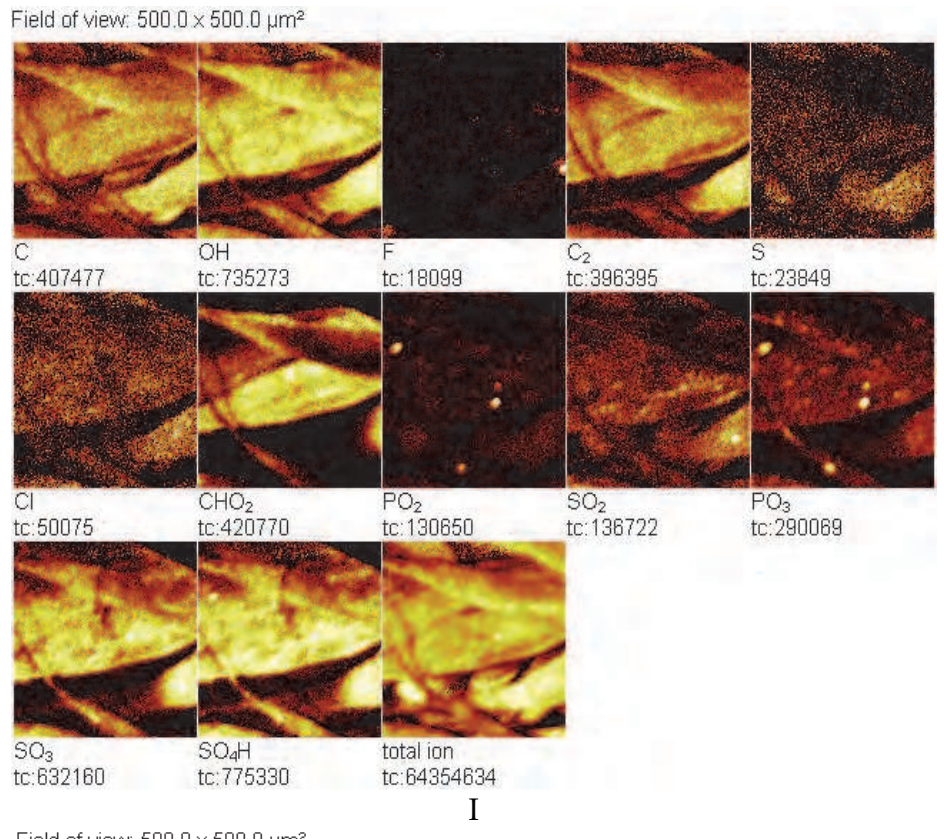

Field of view: $500.0 \times 500.0 \mu \mathrm{m}^{2}$

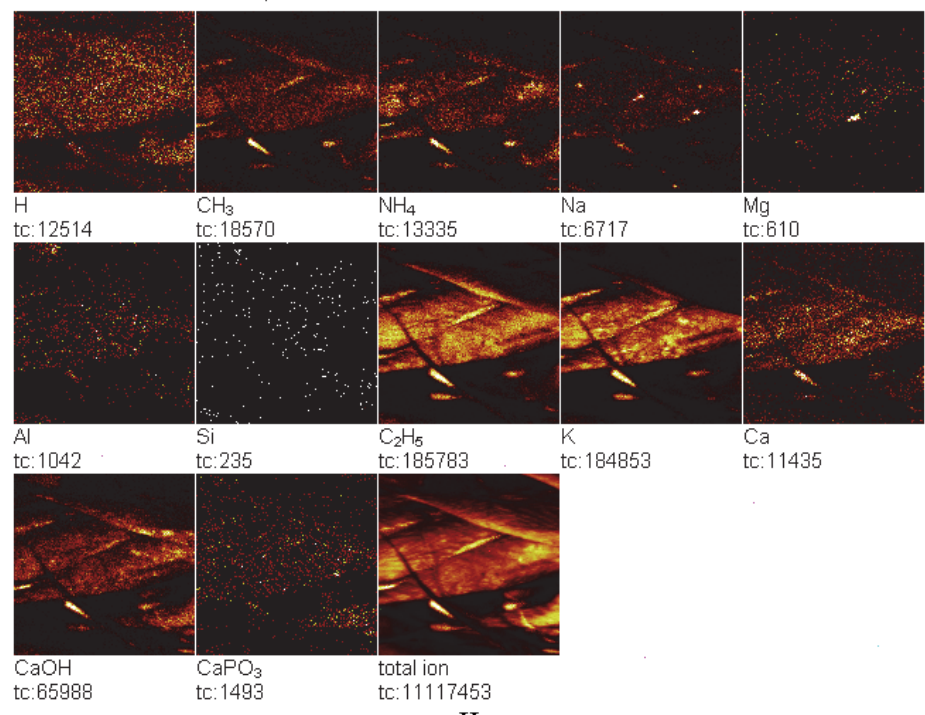

II

Fig. 9. ToF-SIMS positive (I) and negative I (II) on images of moss from the control site

The obtained ToF-SIMS spectra showed that the peak intensities of $\mathrm{Ca}^{+}$, and $\mathrm{PO}_{2}^{-}$ions characteristic of gypsum are significantly different for moss and lichen samples collected from the polluted and control sites (Fig. 10). These results confirmed that the phosphate waste disposal place has an impact on the surrounding environment. 

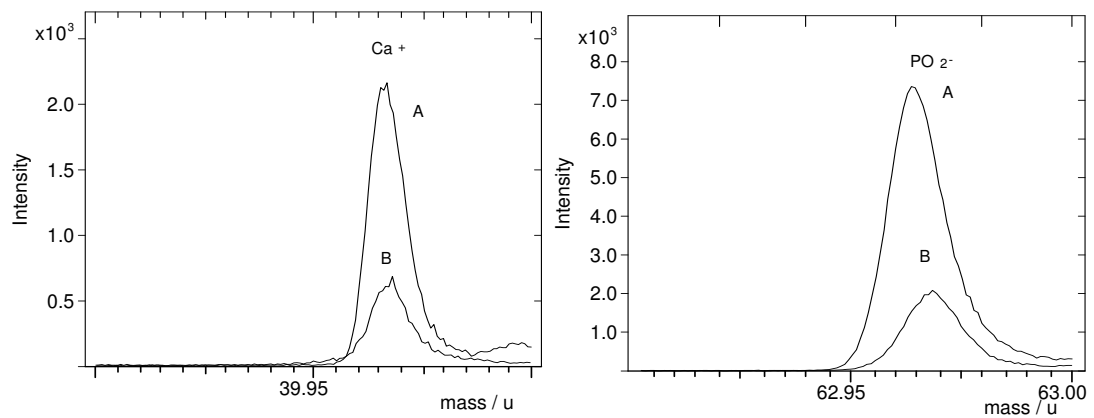

I
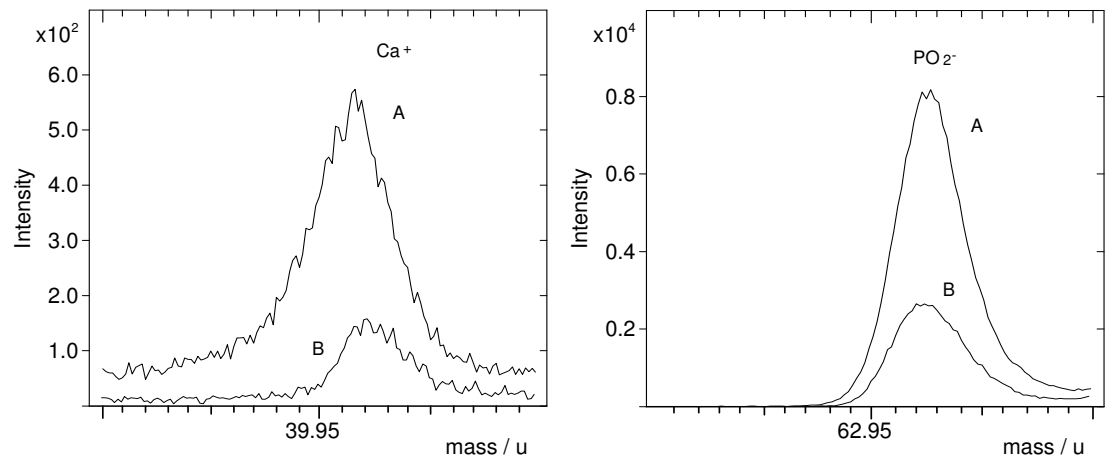

II

Fig. 10. $\mathrm{Ca}^{+}$, and $\mathrm{PO}^{2-}$ ion peaks from the ToF-SIMS spectra of the moss (I) and lichen (II) from Wiślinka (A) and from the control site (B), respectively

The analysis of crystalline phases of different phosphogypsum samples confirmed that this waste by-product is mainly composed of calcium sulfate dihydrate. Additionally, for comparison purposes four phosphogypsum samples obtained directly from the production line and originating from Morocco, Syria, Tunisia and Kola phosphate rocks were investigated. Three of them were formed as a result of the dihydrate method of production of phosphoric acid (Morocco, Syria, Tunisia), while only one sample was created by the hemihydrate process. In general, all gypsum samples show almost the same crystalline composition with minor exceptions. Anhydrite $\left(\mathrm{CaSO}_{4}\right)$, bassanite $\left(\mathrm{CaSO}_{4} \cdot \mathrm{H}_{2} \mathrm{O}\right), \mathrm{CaO}$, $\mathrm{CaPO}_{3}(\mathrm{OH}) \cdot 2 \mathrm{H}_{2} \mathrm{O}$ (brushite), $\mathrm{SiO}_{2}, \mathrm{Fe}_{3} \mathrm{O}_{4}, \mathrm{H}_{3} \mathrm{PO}_{4}, \mathrm{SrSO}_{4}, \mathrm{Na}_{2} \mathrm{SiF}_{6}, \mathrm{Na}_{5} \mathrm{Fe}_{3} \mathrm{~F}_{14}$ were present on diffraction patterns (Fig. 11). The results show as well that magnetite was detected only in samples from Tunisia and Syria, whereas $\mathrm{Na}_{2} \mathrm{SiF}_{6}$ was detected in samples from Kola and Tunisia. $\mathrm{Na}_{5} \mathrm{Fe}_{3} \mathrm{~F}_{14}$ was detected in apatite-based phosphogypsum. No fluorine compounds were detected in the analysed samples because the XRD spectrum was dominated by the peaks of bassanite and gypsum.

Similarities observed in XRD spectra of older phosphogypsum collected directly from the stack and phosphogypsum obtained from Morocco phosphate rock suggest the same source of rock of both materials. Some amount of $\mathrm{P}_{2} \mathrm{O}_{5}$ or $\mathrm{SiO}_{2}$ in phosphogypsum material identified with the XRD technique can be attributed to the residues of unreacted particles of 
phosphate rock. Burshite is an apatite precursor, hence its presence in the phopshogypsum waste is not surprising.

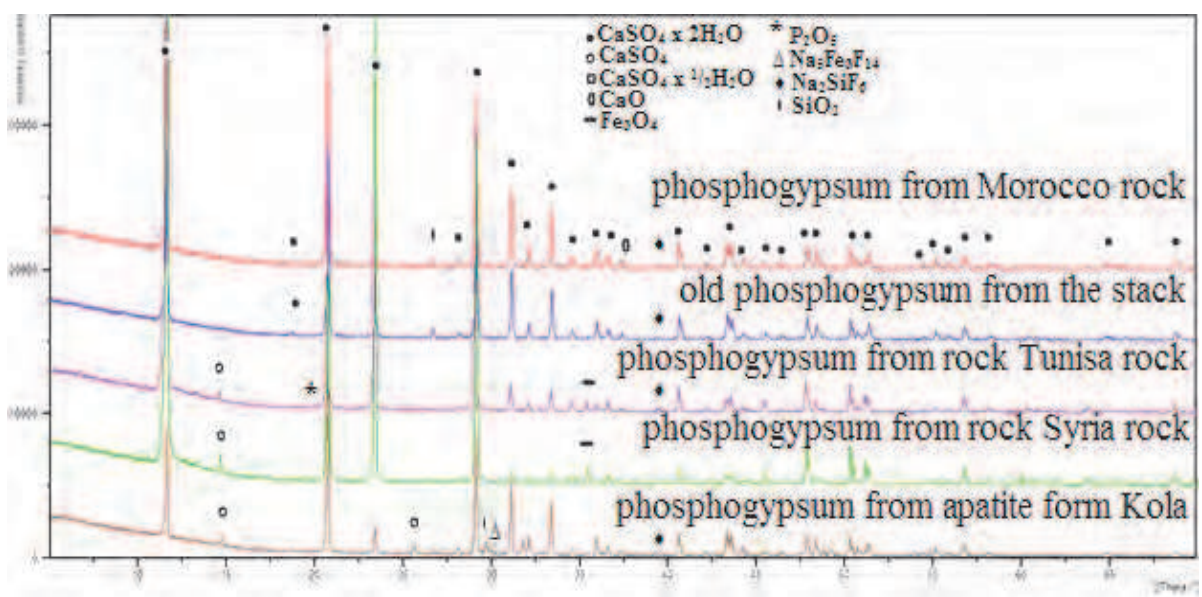

Fig. 11. Diffraction patterns of various phosphogypsum samples collected directly from the stack (old) with an unknown source of phosphate rock and obtained from the production line (originating from Morocco, Syria, Tunisia and Kola rocks).

In order to obtain information about the possible migration of phosphogypsum impurities into the environment, waste material was collected from different places of stack. The comparison of XRD patterns (Fig. 12) of two phosphogypsum samples proved that the composition is almost the same with hydroxyapatite, calcium sulfate dihydrate, bassanite (hemihydrate form) and anhydrite as main components. The only difference is the presence of celestine $\left(\mathrm{SrSO}_{4}\right)$ in the sample collected near the trench. The lack of celestine in the composition of fresh phosphogypsum can support the suggestion that the process of leaching of phosphogypsum contaminants and their subsequent transportation into the adjacent environment take place. In general, strontium, which is present in sedimentary formations, usually accompanies calcium and as a result of transformation of deposits enriched with $\mathrm{Ca}$, strontianite is created $\left(\mathrm{SrCO}_{3}\right)$. Strontianite after the reaction with sulphur may form celestine. It is thought that this compound may pose a threat to the local environment by an excessive concentration of a highly soluble amount of strontium. Probably rain water, which flows down the stack surface, causes the accumulation of $\mathrm{Sr}$ in the trench surrounding the dump in the acid environment. Moreover, the distribution of this element is facilitated by the tendency of Sr to migrate to the surface formations. Some previous studies concerning the analysis of the level of selected elements in surface waters (Vistula River) confirmed that the samples collected in the vicinity of the waste dump contained an elevated concentration of Sr (Dembska et al, 2006). On the contrary, fresh phosphogypsum seems to be more enriched with $\mathrm{H}_{3} \mathrm{PO}_{4}$. According to literature, the increase in deposition time causes the decrease in acidity by washing out the residue of acids from the production of phosphoric acid (Nowak, 2006). 


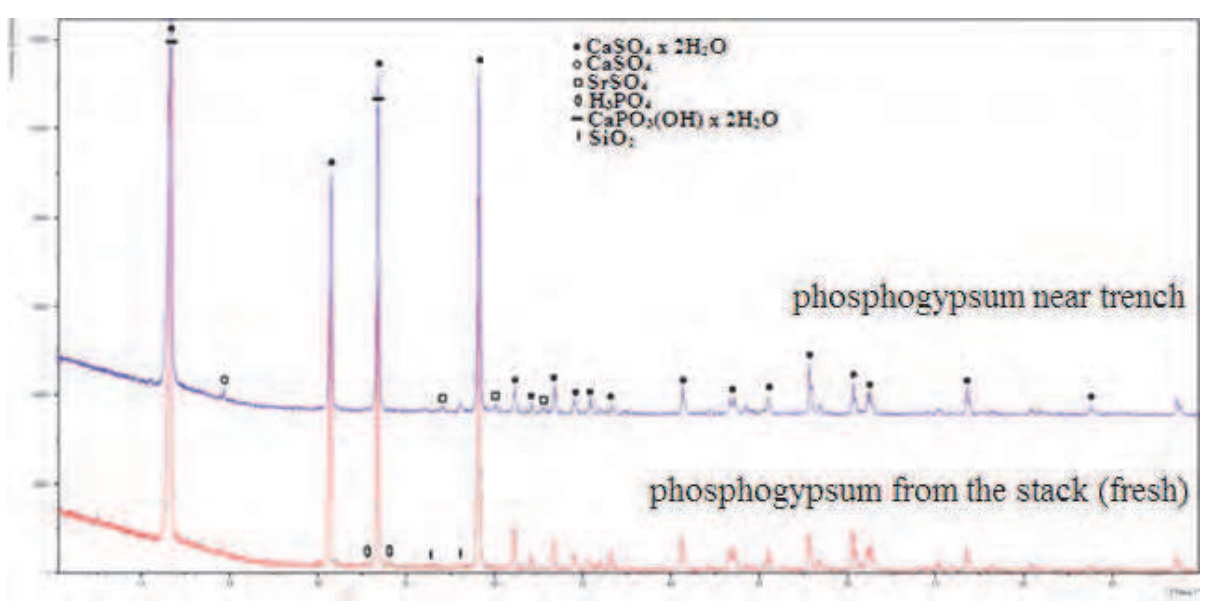

Fig. 12. Diffraction patterns of two phosphogypsum samples taken from the same area

XRD analysis showed that biological samples contain a limited amount of crystalline phases (Fig. 13). On the other hand, the XRD diffraction patterns did not confirm the existence of any compounds characteristic of deposited waste material on the surface of biological material taken from the area situated near the dump, probably due to a small amount of contaminants accumulated on the surface in relation to the whole sample. Generally, in the case of the biological material, obtained diffraction patterns revealed that quartz $\left(\mathrm{SiO}_{2}\right)$ was the main component.

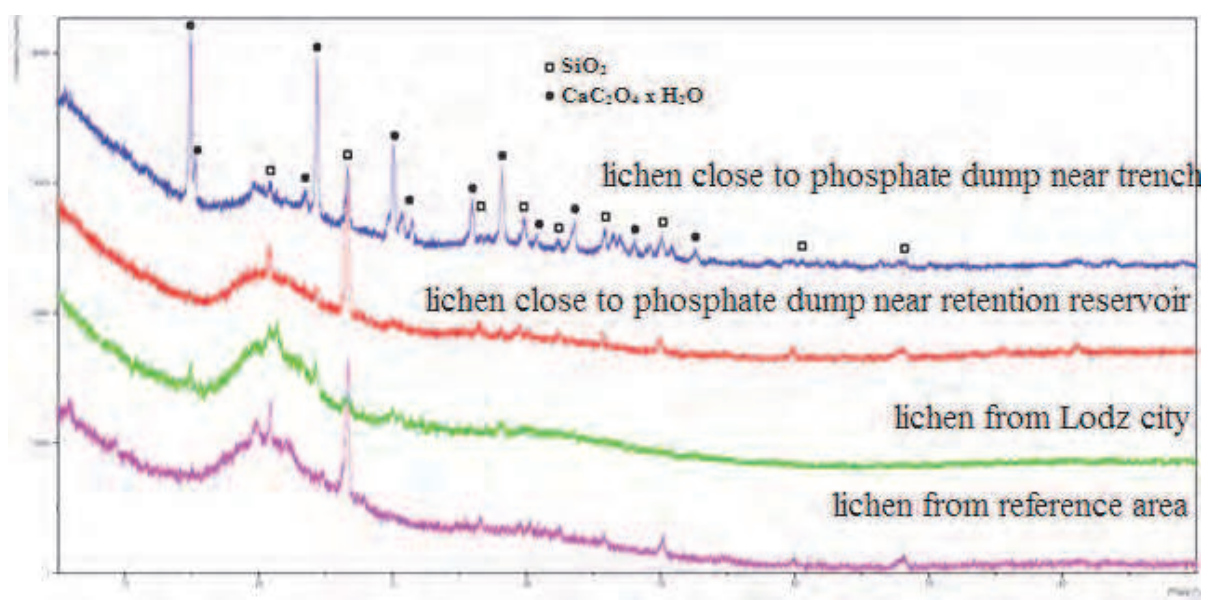

Fig. 13. Diffraction patters of lichen samples collected from the area situated in the neighborhood of the phosphate waste disposal place (near trench and retention reservoir), from urbanized Lodz area and from the reference clean site (Lagiewniki Forest).

The potential source of $\mathrm{SiO}_{2}$ could be contamination from soil or fly ashes. Small differences observed on the diffraction patterns of various biological samples can be attributed to different forms of $\mathrm{SiO}_{2}$ - crystalline and amorphous. Additionally, some biological samples 
contained $\mathrm{CaC}_{2} \mathrm{O}_{4} \cdot \mathrm{H}_{2} \mathrm{O}$ (whewelite). This organic mineral is created as a result of precipitation of calcium oxalates, leached from organic material and it does not seem to be specific for a sample collection place.

It should be emphasized that a detailed interpretation of XRD results was limited by a considerable amount of amorphous compounds present in the studied materials and other organic phases characteristic of plant material, whose identification was not possible due to the lack of adequate diffractive standards in the data powder base. Moreover, the detection limit of the technique used is above $0.5 \%$, which limits the verification of the presence of trace components. Although, all analysed samples showed similar profiles of diffraction patterns, some essential differences among samples collected from ecologically clean areas, metropolitan area or the surroundings of waste disposal site were observed. The samples were collected after the recultivation process (the surface of stack was covered with a mixture of soil, grass seeds and sewage sediments), which could significantly reduce the effect of dusting on the local area.

\section{Conclusions}

The obtained SEM-EDS and ToF-SIMS results showed that the surface of biological material collected in the vicinity of the phosphatic fertilizer waste dump was covered with particles whose chemical composition corresponds to the chemistry and morphology of stockpiled waste by-product. The performed surface studies of biological material revealed that the observed particles showed various morphology (size and shape) but are characterized by similar chemical composition. It was found that gypsum is a main component of the analyzed particles with the admixture of $\mathrm{Al}, \mathrm{Si}, \mathrm{K}, \mathrm{Fe}, \mathrm{Na}, \mathrm{P}, \mathrm{F}$, and $\mathrm{S}$. The presence of elements and molecules typical of phosphogypsum and its impurities on the surface of biological indicators suggests that there exists a dusting process form the waste disposal place, which can pose a health hazard to the inhabitants by potential inhalation of the material carried by wind and containing toxic substances including fluorine and heavy metals due to the fact that many of the deposited particles consisted of the fraction less than $10 \mu \mathrm{m}$. Moreover, the degree of covering of the biological surface by anthropogenic dust decreased with the distance from the waste disposal site. This observation can suggest that the dusting process from the waste disposal place is responsible for the phosphogypsum contamination of phosphatic fertilizer dump neighborhood.

The XRD technique revealed significant differences between phosphogypsum material: fresh and older. Moreover, various phase composition in both phosphate rock and phosphogypsum was identified. X-ray diffraction patterns of phosphogypsum in general show mainly calcium sulfate dehydrate with impurities such as silicon oxide. In the case of phosphogypsum sample taken from the trench around the stack, in addition to the diffraction peak of gypsum, also calcium and strontium sulfate as well as phosphoric acid peaks were observed in comparison with the fresh material.

Phosphate rock was composed of fluorapatite, silicon oxide, calcite, magnetite or perovskite. It was also stated that during the time of storage, the acidity of waste by-product decreases to the deeper parts of dump due to the washing process. Moreover, the presence of strontium sulphate in fresh prosphogypsum may suggest that $\mathrm{Sr}$ can be introduced into the surrounding environment by the dusting process, while the content of this element in waste reaches even $1 \%$. Unfortunately, it was not possible to detect compounds characteristic of stockpiled phosphogypsum on the surface of biological samples due to the low surface 
concentration. It should also be emphasized that the samples were taken after the recultivation process with sewage sludge, which could considerably reduce the dusting process from the dump.

This study also showed a versatile application of ToF-SIMS and SEM-EDS methods as powerful tools for the identification of particulate matter on the surface of chosen biological samples as well as for the assignment of individual particles to their potential origin. Surface-analysis techniques make it possible to combine information about both changes of the surface of bioindicators and the state and source of environmental pollution. Our results also confirmed the usefulness of adapting moss and lichen samples (apart from their well known accumulation ability) as notable trapping organisms of mostly windblown airborne particles.

\section{Acknowledgment}

Authors thank to dr Joanna Bojarska from the Institute General and Ecological Chemistry at Technical University of Lodz for XRD measurements.

\section{References}

Al-Masri M.S., Amin Y., Ibrahim S., Al-Bich F., Applied Geochemistry 2004; 19, 747.

Arocena J.M., Rutherford P.M., Dudas M.J., The Science of the Total Environment 1995; 162, 149.

Dembska G., Grynkiewicz M., Wiśniewski S., Aftanas B., Wiadomości Chemiczne, vol. 2006, $60,302$.

Goldstein J.I., Newbury D.E., Joy D.C., Roming A.D., Lyman C.E., Fiori C., Lifshin E., Scanning Electron Microscopy and X-Ray Microanalysis, Plenum Press, New York, 1992.

Kempson I.M., Skinner W.M., The Science of the Total Environment 2005; 338, 213.

Nowak W., Rekultywacja biologiczna hałdy fosfogipsu w Zakładach Chemicznych Wizów S.A., Zeszyty Naukowe Uniwersytetu Przyrodniczego we Wrocławiu, vol. 545, 195203, Rolnictwo LXXXVIII, Wrocław 2006.

Robinson J.W., Undergraduate instrumental analysis, Marcle Dekker, Inc., New York, 1995. Rutherford PM., Dudas M.J., Arocena J.M., Waste Management and Research 1995; 13, 407. Seyama H., Applied Surface Science 2003; 203-204, 745.

Seyama H., Soma M., Analytical Sciences 2003; 19, 487.

Szczepaniak K., Biziuk M., Environmental Research 2003; 93, 221.

Szynkowska M.I., Scanning Electron Microscopy. Encyclopedia of Analytical Science (Eds. P.J. Worsfold, A. Townshend and C.F. Poole), Elsevier, Oxford, 2005, pp. 134-142.

Szynkowska M. I., Pawlaczyk A., Paryjczak T., Polish Journal of Chemistry, 2008a, 82, 32.

Szynkowska M.I., Pawlaczyk A., Rogowski J., Applied Surface Science, 2008b, 255/4, 1165.

Williamson B.J., Mikhailova I., Purvis O.W., Udachin V., The Science of the Total Environment 2004; 322, 139. 


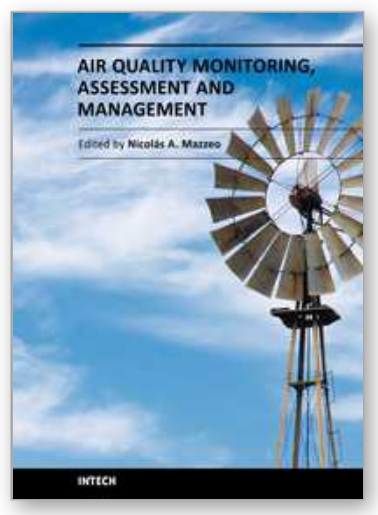

\author{
Air Quality Monitoring, Assessment and Management \\ Edited by Dr. Nicolas Mazzeo
}

ISBN 978-953-307-317-0

Hard cover, 378 pages

Publisher InTech

Published online 08, July, 2011

Published in print edition July, 2011

Human beings need to breathe oxygen diluted in certain quantity of inert gas for living. In the atmosphere, there is a gas mixture of, mainly, oxygen and nitrogen, in appropriate proportions. However, the air also contains other gases, vapours and aerosols that humans incorporate when breathing and whose composition and concentration vary spatially. Some of these are physiologically inert. Air pollution has become a problem of major concern in the last few decades as it has caused negative effects on human health, nature and properties. This book presents the results of research studies carried out by international researchers in seventeen chapters which can be grouped into two main sections: a) air quality monitoring and b) air quality assessment and management, and serves as a source of material for all those involved in the field, whether as a student, scientific researcher, industrialist, consultant, or government agency with responsibility in this area.

\title{
How to reference
}

In order to correctly reference this scholarly work, feel free to copy and paste the following:

Malgorzata Iwona Szynkowska, Aleksandra Pawlaczyk and Jacek Rogowski (2011). Characterization of Particles Transmitted by Wind from Waste Dump of Phosphatic Fertilizers Plant Deposited on Biological Sample Surfaces, Air Quality Monitoring, Assessment and Management, Dr. Nicolas Mazzeo (Ed.), ISBN: 978953-307-317-0, InTech, Available from: http://www.intechopen.com/books/air-quality-monitoring-assessmentand-management/characterization-of-particles-transmitted-by-wind-from-waste-dump-of-phosphatic-fertilizersplant-de

\section{INTECH}

open science | open minds

\section{InTech Europe}

University Campus STeP Ri

Slavka Krautzeka 83/A

51000 Rijeka, Croatia

Phone: +385 (51) 770447

Fax: +385 (51) 686166

www.intechopen.com

\section{InTech China}

Unit 405, Office Block, Hotel Equatorial Shanghai

No.65, Yan An Road (West), Shanghai, 200040, China

中国上海市延安西路65号上海国际贵都大饭店办公楼405单元

Phone: +86-21-62489820

Fax: $+86-21-62489821$ 
(C) 2011 The Author(s). Licensee IntechOpen. This chapter is distributed under the terms of the Creative Commons Attribution-NonCommercialShareAlike-3.0 License, which permits use, distribution and reproduction for non-commercial purposes, provided the original is properly cited and derivative works building on this content are distributed under the same license. 